\title{
Mandibular Fractures as Related to the Site of Trauma and the State of Dentition
}

DONALD F. HUELKE, ALPHONSE R. BURDI, and CHARLES E. EYMAN

Department of Anatomy, The University of Michigan, Ann Arbor, Michigan

With sufficient energy imparted to the mandible by an impact, the bone will fracture. But where? Is the location of mandibular fractures haphazard and arbitrary, or are there predisposing factors which tend to influence this location? No doubt the shape of the bone itself plays an important role in determining the location of some of the fractures. The narrow neck of the mandible, with its reduced cross-sectional area, is probably less strong than the body or the symphysis. Also in this regard the magnitude of the energy of the impact will be significant. If the amount of energy imparted to the mandible is above the elastic limit of the bone, a fracture will occur, with most of the energy being dissipated in producing the one fracture. However, if the magnitude of the energy greatly exceeds the elastic limit, more fractures are likely to be produced.

Does the state of dentition or the site of trauma have any influence on the location of these fractures? Up to this time, no clinical or experimental evidence has been presented to substantiate or refute these questions. It is the purpose of this report to present data regarding the relationship of the location of mandibular fractures and number of fractures with the site of impact, the state of dentition, and the age of the individual.

\section{MATERIALS AND METHODS}

For this study, 319 case histories of mandibular fractures from The University Hospital, The University of Michigan, Ann Arbor, were analyzed. These case histories were also used in a previous study of mandibular fractures. ${ }^{1}$

In this study the data were placed in one of five categories based on the state of dentition of the mandible prior to trauma. The first three categories are edentulous, dentulous, and deciduous or mixed dentition. Patients with a number of teeth missing in a certain area of the mandible were placed in a fourth category called "quadrants missing"; these areas included the right and left posterior regions and, at times, the anterior region. The fifth category included all patients who had one or several scattered mandibular teeth missing; almost always these were molar teeth, usually the second and third molars. Each category was then subdivided, using a specific site of trauma for each subdivision. In all cases, information on the amount of energy of the impact imparted to the bone was not available.

The locations of the fractures were presented as subcondylar, at the neck of the

This investigation was supported in part by U.S.P.H.S. research grant D-895C1 from the National Institute of Dental Research, National Institutes of Health.

Received for publication March 6, 1961. 
mandible; angle-body, fractures located between the gonial angle and the mental foramen; chin fractures, between the mental foramina; and "other" fractures, including those of the ramus, alveolar bone alone, and the coronoid process.

The various sites of trauma used in this study were: chin point, the symphysis; lateral chin, between the symphyseal area and the corner of the mouth; chin area, the region between the corners of the mouth (this term was coined when some case histories stated the site of trauma as "to the chin" with no other information available; it refers to the anterior part of the jaw); angle or body, the side of the mandible; unknown, the site of trauma not known.

After the data were grouped into the various categories, they were subjected to statistical analysis by applying the chi-square test for significant association. Quite briefly, this method tests the hypothesis that two or more attributes are associated for causes other than a random (chance or accidental) combination. This test provides an excellent tool whereby objective statements can be made concerning non-metric (unmeasurable) data. The total number of cases that had a particular pair of attributes (for example, subcondylar fractures and dentulous jaws) was recorded in the proper square or cell (see Table 1), and these were termed the "observed frequencies."

TABLE $1^{*}$

ASSOCIATION BETWEEN STATE OF DENTITION AND LOCATION OF FRACTURE



$* N=575$ (sample size) $\{319$ cases $\} ;$ D.F. $=12 ; \mathbf{X}^{2}=29.051 ; P=32.909(0.001), 26.217(0.01), 24.054(0.02), 21.026(0.05)$

Within each cell, the value above the diagonal line is the computed expected frequency of the occurrence of the particular association. The value below the diagonal line is the observed or actual frequency of the particular association. The values in parentheses below the diagonal line within each cell represent the percentage of the particular observed frequency to all others $n$ the table. The occurrence of a " +" above the diagonal line, below the expected value, indicates that the cell has the highest $n$ the table. The occurrence of a "+" above the diagonal line, below the expected value, indicates that the cell has the highest
observed value for the particular column. A zero beneath the expected frequency indicates that the cell has the highest observed frequency for that particular row. 
"Expected frequencies" were then computed. The expected frequencies represented the number of cases of the particular pair of attributes which would be expected to occur in the sample as a function of sampling error, that is, those cases in the sample which were in association purely by chance alone. Expected frequencies were calculated by multiplying the total number of one attribute--say subcondylar fractures (Table 1) - by the total number of another, dentulous jaws, and dividing by the grand total of all cases presented in the table $(206 \times 197 \div 575=70.58)$. For each cell the difference between the observed and expected frequencies was squared, and this was divided by the expected frequncy. All these results were then added to obtain the chisquare value. The formula and a fuller explanation of the test can be found in any basic statistical text.

Once the chi-square value had been obtained, statistical tables were consulted, in order to determine the probability of obtaining the observed value if there were mere random (chance) association between the given attributes, taking into account the proper "degrees of freedom." The degrees of freedom were calculated by multiplying the number of rows in the table minus one, times the number of columns minus one. Using Table 1 as an example, there are four columns and five rows. The degrees of freedom then are $(4-1) \times(5-1)=12$.

In this study, non-random associations of the attributes, that is, results not due to chance alone, were considered to be demonstrated only when the chi-square values exceded the 0.01 level of probability. That is to say, the results were due to chance and chance alone in one out of 100 samples. Probability values at the $0.001,0.02$, and 0.05 levels are included in each table to provide comparative information. In view of the high values of all the chi-square tests included herein, Yates's correction factor was not employed except to verify the assumption that its omission did not significantly alter the results.

Stated simply, the chi-square test allows the investigator to ask, "What is the probability that the association observed is due to chance alone?" Reference to Table 1 shows that the chi-square value was 29.051 when the state of dentition and the location of fractures were compared. The probability $(P)$ at the 0.01 level was 26.217 , indicating that these results would have been expected to occur only one time in 100 as a result of sampling error, that is, through chance alone in sampling. Since the obtained chi-square value (29.051) exceeded $P$ at the 0.01 level $(26.217)$ and, in fact, was approximately halfway between the values for the 0.01 and 0.001 levels, there was considerable justification for inferring that the state of dentition was significantly associated with the location of the mandibular fracture. The chi-square test eliminated subjective inference and objectively demonstrated that the association would be due to chance in less than one out of 100 randomly selected fracture cases.

The chi-square test is always set up on a "null" hypothesis. The null hypothesis is an assumption that the association in question is random and is not significant, being due only to chance. In Table 1 the hypothesis is that there is no association between the state of dentition and the location of fracture. The hypothesis, having been refuted (see above), allows for the statement that there is an association which is not due to chance alone. Therefore, "proof" lies in the refutation of the null hypothesis.

Although there is no adequate statistical method whereby the most significant cell associations can be determined within a given chi-square contingency table, it is pos- 
sible to determine which groups of attributes are randomly or non-randomly associated within the given table. This was effected by applying additional chi-square tests to the data. Each table was examined to determine the location of the cell with the highest observed frequency within each column and within each row. These are indicated schematically within each of the chi-square tables; a plus sign designates the cell with the highest observed frequency of all the cells in a particular column, while a zero indicates the cell with the highest observed frequency of all the cells in a particular row.

Once this has been done, additional questions may be asked of the data through utilization of the chi-square test. As regards the pattern of the "+" signs (columns), the null hypothesis is that the association of these attributes to each other is not significant. The same hypothesis is made for the distribution of the highest observed frequencies by rows within the particular table. A third hypothesis is that the residual columns and rows are not significantly associated. Refutation of either or both of the first two null hypotheses indicates that, within the over-all table, certain groups of attributes are non-randomly associated. Acceptance of the null hypothesis when the chi-square test is applied to the residual cells indicates that they are associated only in a random manner.

This can be demonstrated by referring to Table 1 . Here the distribution of the cells with the highest observed frequencies within each column is in the first two rows ("Individual Teeth Missing" and "Dentulous" jaws). The distribution of the cells with the highest observed frequencies for each row falls within the "Subcondylar" and "Angle-Body" fracture-site columns.

Applying the chi-square test to the first two rows, the chi-square value was 12.487, and, with three degrees of freedom, $P=11.345(0.01)$ and $16.268(0.001)$. Thus the association of dentulous jaws and jaws with individual teeth missing with the various fracture sites was considered to be non-random.

Applying another chi-square test to the cells which comprise the "Subcondylar" and "Angle or Body" fracture-site columns, chi-square equaled 13.020; with four degrees of freedom for this particular test, $P=11.668(0.02)$ and $13.277(0.01)$. The null hypothesis was not refuted, but the results were so close to the 0.01 confidence level that the non-randomness of the association was accepted with some reservations.

A final chi-square test was applied to the two residual columns and rows. Results indicated that the chi-square value was 2.519 , and, at two degrees of freedom, $P=2.408(0.30), 3.219(0.20)$. Therefore, the null hypothesis was not refuted, and the association between these residual cells was quite random.

From these additional tests a further statement as to the association between the state of dentition and the location of fracture can be made. The association seemed to be more non-random in jaws with individual teeth missing and in fully dentulous jaws than it was in edentulous, quadrants of teeth missing, or deciduous and mixed dentition categories of jaws. Furthermore, it is suggested, with reservations, that the association between all dental states and subcondylar and angle or body fractures is more non-random than is the case with chin or other fracture loci. Finally, the association between chin and other fracture sites with jaws which are edentulous, have quadrants of teeth missing, or have deciduous and mixed dentition must be considered to be random. 


\section{RESULTS}

The association between the state of dentition and the location of the fracture is presented in Table 1 . On the basis of percentages alone, the relation between edentulous jaws and fracture location appeared significant, for, in this group, 61 per cent of the fractures were in the angle-body region, with only 22 per cent in the subcondylar area. In dentulous jaws, more fractures were found in the subcondylar than in the angle or body area. There appeared to be no difference in the frequency of subcondylar and angle or body fractures in the individual teeth missing or in the quadrants missing groups. However, these percentages are misleading, as indicated below by the results of the chi-square test.

The null hypothesis for the data in Table 1 has been given above (see "Materials and Methods"), and this hypothesis has been refuted. Additional chi-square tests on

TABLE 2

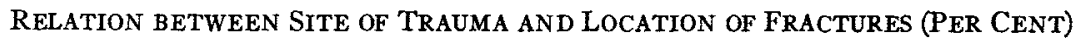

\begin{tabular}{|c|c|c|c|c|c|c|c|c|c|c|c|c|}
\hline \multirow{3}{*}{$\begin{array}{l}\text { Site of } \\
\text { Trauma }\end{array}$} & \multicolumn{12}{|c|}{ Fracture Location } \\
\hline & \multicolumn{3}{|c|}{ Subcondylar } & \multicolumn{3}{|c|}{ Angle or Body } & \multicolumn{3}{|c|}{ Chin } & \multicolumn{3}{|c|}{ Other } \\
\hline & $\begin{array}{l}\text { Edent- } \\
\text { ulous }\end{array}$ & $\begin{array}{l}\text { Decid. } \\
\text { and } \\
\text { Mixed }\end{array}$ & $\begin{array}{l}\text { Quads. } \\
\text { Miss- } \\
\text { ing }\end{array}$ & $\begin{array}{l}\text { Edent- } \\
\text { ulous }\end{array}$ & $\begin{array}{l}\text { Decid. } \\
\text { and } \\
\text { Mixed }\end{array}$ & $\begin{array}{l}\text { Quads. } \\
\text { Miss- } \\
\text { ing }\end{array}$ & $\begin{array}{c}\text { Edent- } \\
\text { ulous }\end{array}$ & $\begin{array}{c}\text { Decid. } \\
\text { and } \\
\text { Mixed }\end{array}$ & $\begin{array}{l}\text { Quads. } \\
\text { Miss- } \\
\text { ing }\end{array}$ & $\begin{array}{c}\text { Edent- } \\
\text { ulous }\end{array}$ & $\begin{array}{c}\text { Decid. } \\
\text { and } \\
\text { Mixed }\end{array}$ & $\begin{array}{l}\text { Quads. } \\
\text { Miss- } \\
\text { ing }\end{array}$ \\
\hline $\begin{array}{l}\text { Chin point... } \\
\text { Lateral chin. } \\
\text { Chin area... } \\
\text { Angle or body } \\
\text { Unknown... }\end{array}$ & $\begin{array}{c}58 \\
20 \\
13 \\
13 \\
\ldots \ldots\end{array}$ & $\begin{array}{l}75 \\
22 \\
33 \\
26 \\
25\end{array}$ & $\begin{array}{l}54 \\
36 \\
50 \\
33 \\
50\end{array}$ & $\begin{array}{r}25 \\
60 \\
100 \\
70 \\
80\end{array}$ & $\begin{array}{r}6 \\
45 \\
\ldots \ldots \\
64 \\
25\end{array}$ & $\begin{array}{l}14 \\
36 \\
38 \\
61 \\
50\end{array}$ & $\begin{array}{c}17 \\
\ldots \ldots \\
\cdots \\
9 \\
\ldots\end{array}$ & $\begin{array}{c}19 \\
33 \\
\ldots \ldots \\
\cdots \\
50\end{array}$ & $\begin{array}{c}11 \\
14 \\
\ldots \\
6\end{array}$ & $\begin{array}{r}20 \\
\cdots \\
9 \\
20\end{array}$ & $\begin{array}{r}67 \\
10 \\
\ldots\end{array}$ & $\begin{array}{l}21 \\
14 \\
12\end{array}$ \\
\hline
\end{tabular}

select associations between the dental state and fracture location have, as indicated previously, demonstrated that certain associations by themselves are non-random.

First of all, it seemed to be quite apparent that mandibles which were fully dentulous or lacked individual teeth had the most frequent non-random association with fractures. To a lesser degree, there was a strong possibility that, regardless of the state of the dentition, the most non-random and common fractures were in the subcondylar or the angle-body region of the jaw. Fractures of jaws which lacked dentition or contained deciduous and mixed dentition or had quadrants of teeth missing had no predictable pattern for fractures. The location of fractures at the chin or in other regions as related to all states of dentition likewise was a random event.

It is interesting to note that, in Table 1, the highest observed frequencies by columns and by rows coincided in one cell in two cases. The one cell was that which associated subcondylar fractures with jaws lacking individual teeth; the second cell was that in which angle or body fractures were associated with dentulous jaws.

Table 2 presents data concerning the relation between the site of trauma and fracture location. Each of the sample sizes for edentulous, deciduous and mixed dentition, and quadrants missing were too small to allow for application of the chi-square test. 
Therefore, this test was applied only to the dentulous and individual teeth missing groups (Tables 3 and 4 ).

Percentages in Table 2 indicate that impacts to the chin point, irrespective of the state of dentition, produced subcondylar fractures in over half the cases hit on the chin point. Impacts to the lateral chin region, slightly off the mid-line, produced angle or body fractures in approximately one-third to two-thirds of the individuals, more anglebody fractures being produced due to lateral chin blows in edentulous individuals

TABLE 3*

Association between Site of Trauma and Fracture Location in Dentulous JaWs

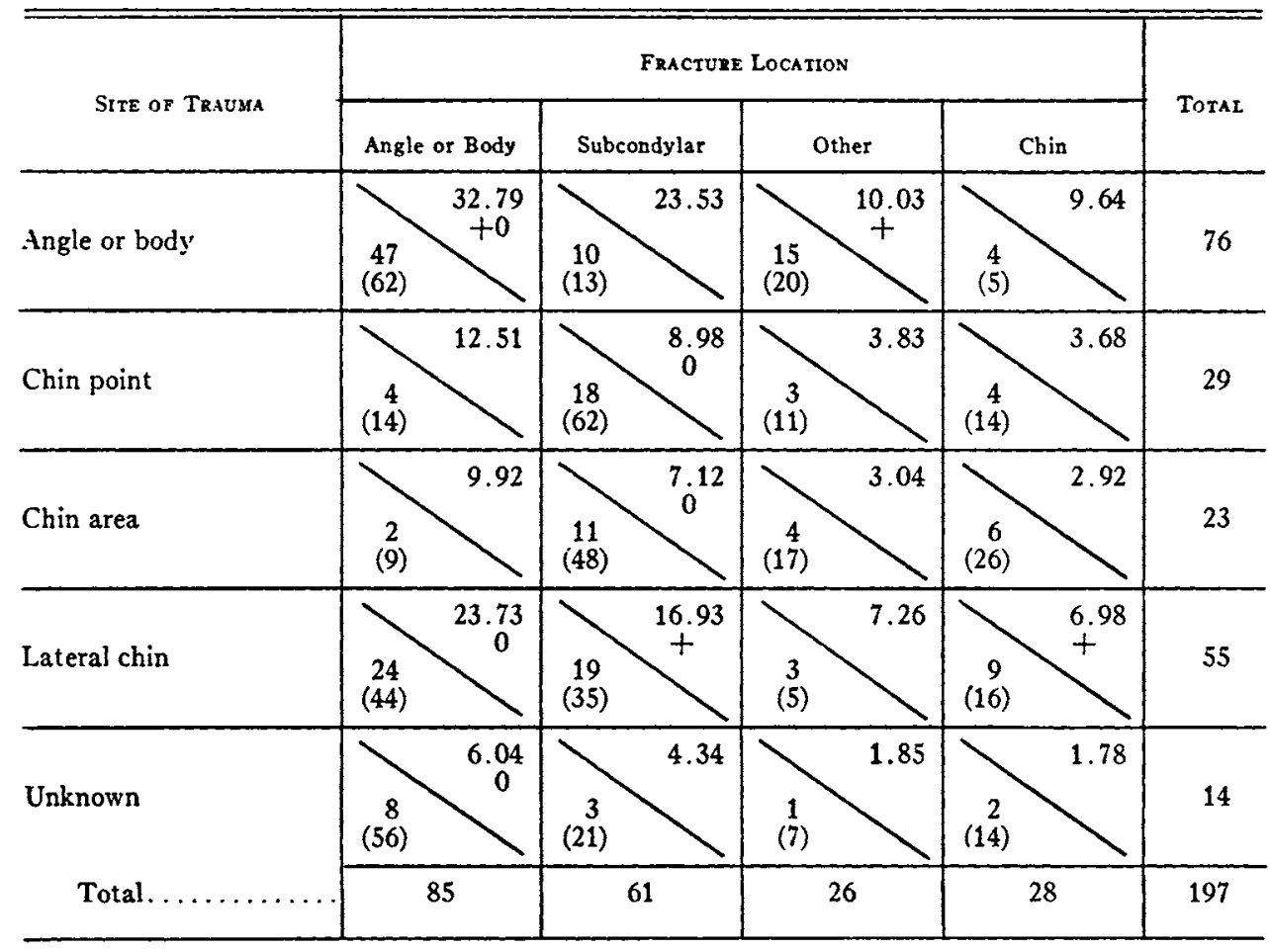

$* N=197\left[113\right.$ cases]; D.F. $=12 ; \mathrm{X}^{2}=48.768 ; P=32.909(0.001), 26.217(0.01), 24.054(0.02), 21.026(0.05)$.

than in any other group. In the deciduous and mixed category, one-third of all fractures due to lateral chin impacts were found in the area of the impact, that is, in the chin region. With impacts to the angle or body region of the mandible, there was a noticeable decrease in subcondylar fractures associated with a high percentage of angle-body fractures in all the various states of dentition.

In regard to correlations between fracture site and location of trauma in the dentulous (Table 3) and the individual teeth missing groups (Table 4), the observed chisquare value was greater than the expected value at the 0.001 level of probability.

In that the null hypothesis has been more than satisfactorily refuted, the statement can be made that there was a significant association between the site of trauma and 
the location of the fracture in dentulous jaws. Thus this association would arise by chance alone in less than one fracture case out of a thousand randomly selected from the population (Table 3 ).

Turning now to an intensive analysis of the associations within Table 3 , plotting of the highest observed frequencies for each column and row indicated a clear-cut pattern. The highest columnar observed frequencies were situated in the rows for the "Angle or Body" and "Lateral Chin" categories. The association of these two trauma

TABLE $4^{*}$

ASSOCIATION BETWEEN Site OF TRAUMA AND FRACTURE LOCATION IN JAWS WITH INDIVIDUAL TEETH MISSING

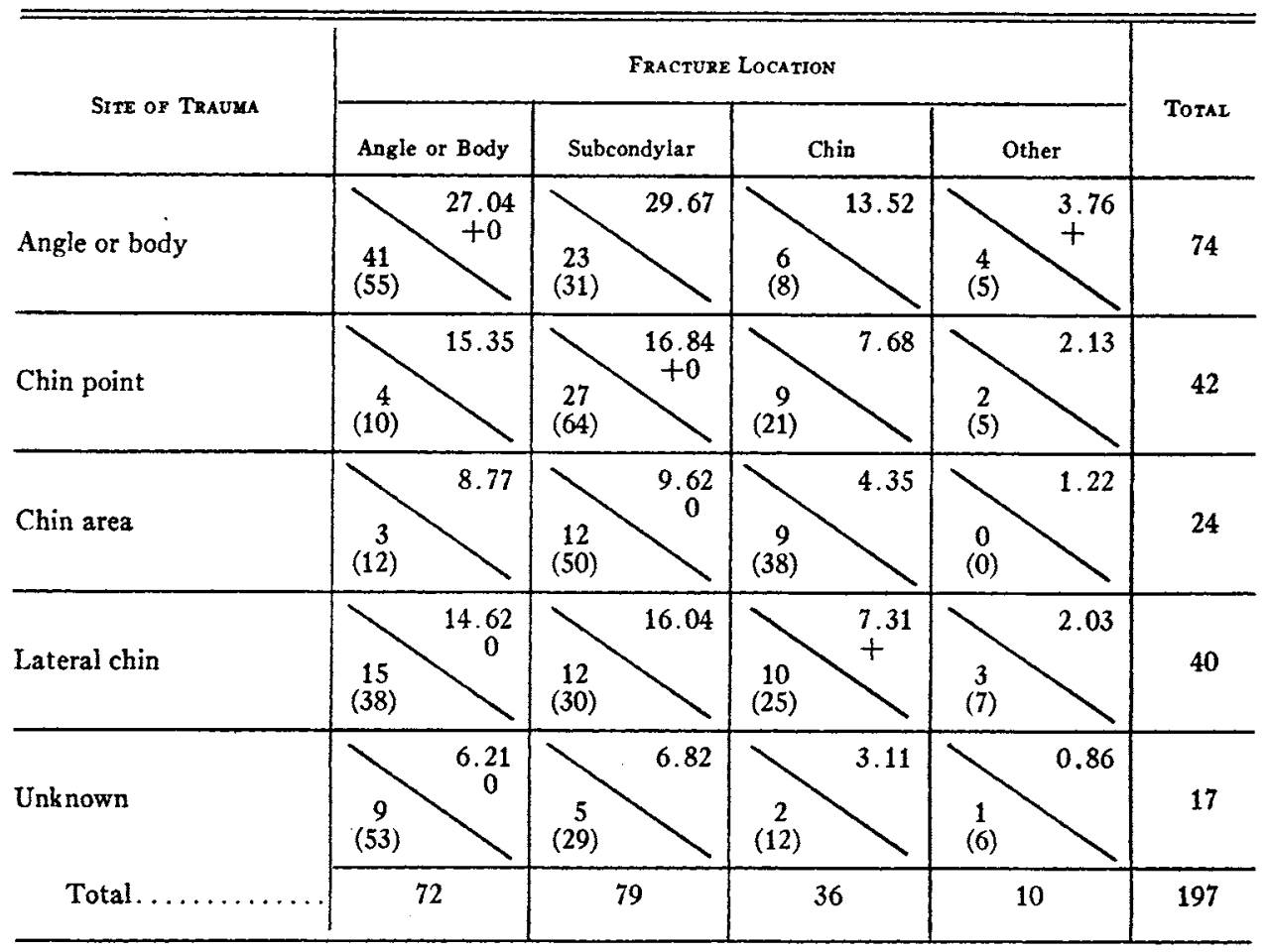

$* N=197\left[101\right.$ cases]; D.F. $=12 ; \mathrm{X}^{2}=41.987 ; P=32.909(0.001), 26.217(0.01), 24.054(0.02), 21.026(0.05)$.

sites with all fracture loci was quite significant; with three degrees of freedom, $P=11.345(0.01)$ and $16.268(0.001)$, and the chi-square value was 17.235 .

The highest observed row frequencies were confined to the "Angle or Body" and "Subcondylar" columns. A chi-square test on the cells concerned yielded a value of 39.149 , and, with four degrees of freedom, $P=13.277(0.01)$ and 18.465 (0.001). Thus in dentulous mandibles, regardless of the site of trauma, there was a very significant non-random association between angle or body and subcondylar fractures.

A third chi-square test for the association between the cells contained in the residual columns and rows did not refute the null hypothesis. The chi-square value was 0.079 ; the degrees of freedom were 2 , at which level $P=0.040(0.98)$ and $0.103(0.95)$. It is 
of interest to note that the only cell in which the highest observed row and column frequency coincided was that associating angle or body trauma sites with angle or body fracture loci.

From the three chi-square tests just discussed, certain inferences are justified. First of all, it was clear that, as regards dentulous jaws, the angle or body region and the lateral chin areas in some way served more effectively to produce a fracture at some point in the jaw. The chin point, chin area, and unknown impact sites, however, served to produce fractures only in a chance manner. Furthermore, it was also apparent that in considering jaws with full dentition, the angle-body, and subcondylar regions were the most susceptible areas for fracture. The chin and other regions had no such predictable "weakness."

The results of the test for significant association between fracture location and site of trauma in patients with individual mandibular teeth missing were statistically significant at the 0.001 level of probability (Table 4).

After plotting the cells with the highest observed frequencies by row and column, the distribution suggested that chi-square analyses be made of the angle or body and subcondylar fracture loci and of the angle or body, chin point, and lateral chin trauma sites.

The chi-square analysis of the angle or body and subcondylar fracture sites in jaws with individual teeth missing, regardless of the trauma site, was impressive. The chisquare value was 28.719 ; at four degrees of freedom, $P=13.277(0.01)$ and 18.465 (0.001). This more than satisfactorily refuted the null hypothesis. As was the case when a similar analysis was conducted on Table 3 , it was apparent that the association of angle or body and subcondylar fractures in jaws with individual teeth missing was not a chance event, again suggesting that these two regions of the mandible were very susceptible to fractures.

The chi-square test on the above-mentioned trauma sites also refuted the null hypothesis. In this case, chi-square $=29.336$, and, with six degrees of freedom, $P=16.812(0.01)$ and $22.457(0.001)$. Thus the association between the trauma sites-angle or body, chin point, and lateral chin, regardless of where the fracture was produced-was very non-random in jaws with individual teeth missing. This set of associations was exactly what was found in dentulous jaws (Table 3), with the addition of the chin point trauma site. Again one can infer that these two and possibly three regions played an important role in producing mandibular fractures.

Applying the chi-square test to the residual cells of Table 4, the value was 3.272 ; with one degree of freedom, $P=2.706(0.10)$ and $3.841(0.05)$; thus the null hypothesis was not refuted, and the associations were considered to be random. The cells in which the highest observed column and row frequencies coincided were those which associated the chin point trauma site with subcondylar fractures and angle or body trauma sites with angle or body fractures.

There is justification in asserting that, for jaws with individual teeth missing, the angle or body and the subcondylar regions are predictable as being the expected areas for jaw fractures. The chin or other regions had no explanation for being fracture sites other than by chance. The angle-body, chin point, and lateral chin impact sites can be expected to produce a fracture somewhere in the jaw; but this was not the case when the impact site was the chin area or some unknown region. 
The chi-square analyses of Tables 3 and 4 suggested various parallels and differences. Regardless of whether or not a jaw is dentulous or has individual teeth missing, fractures of the angle or body and the subcondylar regions can be expected to be produced by chance less than once in a thousand cases, regardless of the point of trauma. Furthermore, in jaws which are fully dentulous or lack individual teeth the probability of a fractured jaw when a blow is delivered to the angle or body or the lateral chin regions (regardless of where the fracture may actually occur) is quite high. That is to say, chance as the cause of this event is less than one in one thousand cases. In jaws with individual teeth missing, chin point traumas may be expected to produce equally non-random fractures.

In addition to these observations, it should be noted that the highest observed frequencies which coincided in terms of sites of traumas and fracture loci in both tables

TABLE 5*

ASSOCIATION BETWEEN STATE OF DENTITION AND NUMBER OF FRACTURES

\begin{tabular}{|c|c|c|c|c|c|c|}
\hline \multirow{2}{*}{$\begin{array}{l}\text { No. of } \\
\text { Frac- } \\
\text { TURES }\end{array}$} & \multicolumn{5}{|c|}{ Dentrtion } & \multirow{2}{*}{ TOTAL } \\
\hline & $\begin{array}{l}\text { Deciduous and } \\
\text { Mixed }\end{array}$ & Dentulous & $\begin{array}{l}\text { Quadrants } \\
\text { Missing }\end{array}$ & Edentulous & $\begin{array}{c}\text { Individual } \\
\text { Teeth Missing }\end{array}$ & \\
\hline 1 & $\begin{array}{r}20 \\
(14)\end{array}$ & $\begin{array}{c}58 \\
(38)\end{array}$ & $\begin{array}{r}23 \\
(35)\end{array}$ & $\begin{array}{c}9 \\
(3)\end{array}$ & $\begin{array}{l}44 \\
(9)\end{array}$ & 154 \\
\hline 2 & $\begin{array}{c}4 \\
(6)\end{array}$ & $\begin{array}{c}50 \\
(38)\end{array}$ & $\begin{array}{c}12 \\
(28)\end{array}$ & $\begin{array}{c}18 \\
(13)\end{array}$ & $\begin{array}{r}46 \\
(15)\end{array}$ & 130 \\
\hline $3-6$ & $\begin{array}{c}5 \\
(9)\end{array}$ & $\begin{array}{r}5 \\
(14)\end{array}$ & $\begin{array}{c}11 \\
(31)\end{array}$ & $\begin{array}{r}3 \\
\text { (14) }\end{array}$ & $\begin{array}{c}11 \\
(31)\end{array}$ & 35 \\
\hline Total. & 29 & 113 & 46 & 30 & 101 & 319 \\
\hline
\end{tabular}

$* N=319 ;$ D.F. $=8 ; \mathrm{X}^{2}=29.085 ; P=26.125(0.001), 20.090(0.01), 18.168(0.02), 15.507(0.05)$.

appeared in the cell associating angle or body trauma sites with angle or body fractures. Additionally, in jaws lacking individual teeth there was a similar association for the cell relating chin point traumas with subcondylar fractures. These similarities might suggest that the angle or body region of the mandible was quite liable to fracture when that area was the point of impact.

The chi-square analysis of the state of dentition and the number of fractures (Table 5) indicated a non-random association, in that the chi-square value exceeded the expected value at the 0.001 level of probability. Once more a plot of the highest observed frequencies by rows and columns indicated a regularity. Here the highest observed frequencies for the columns appear in the rows for single and double fractures. Applying the chi-square test yielded a value of 15.797; with four degrees of freedom, $P=13.277(0.01)$ and 18.465 (0.001). The null hypothesis was not refuted, 
but there is a suggestion that the association between single and double fractures was not random.

There is a striking regularity in the identical location of the highest observed values by rows and columns within the table. This, with the suspect refutation of the null hypothesis just presented, we feel adds support to our inference that the number of fractures is significantly associated with the various states of dentition but that particular states of dentition cannot be singled out as being more non-random in this association than in others. Obviously, fractures on the order of three to six in a single

TABLE $6^{*}$

Association between Site of Trauma and NUMber of Fractures

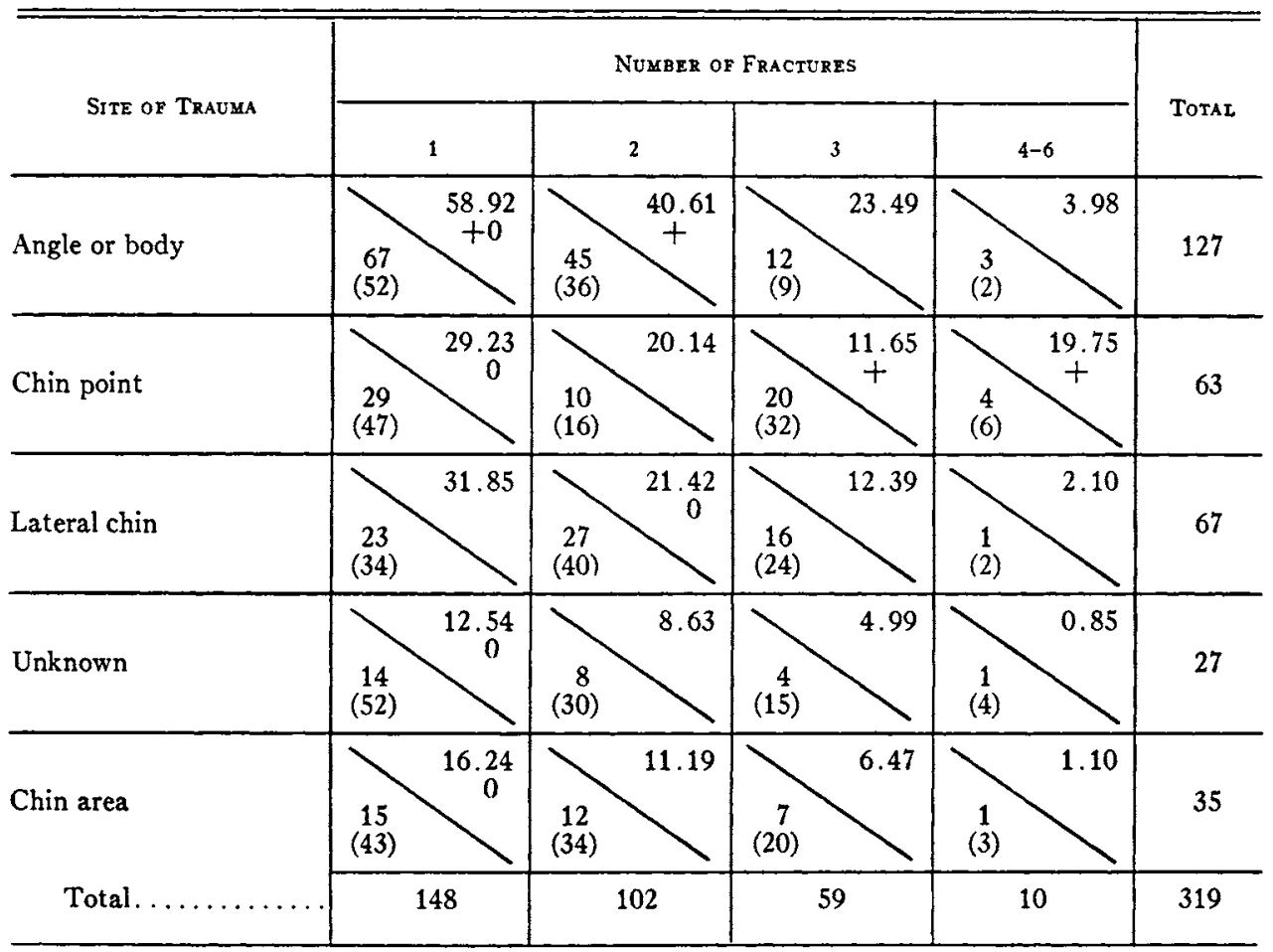

$* N=319 ; \mathrm{D} . \mathrm{F} .=12 ; \mathrm{X}^{2}=26.442 ; P=32.909(0.001), 26.217(0.01), 24.054(0.02), 21.026(0.05)$.

mandible simultaneously should require either a massive impact or multiple impacts. The only cell which was the intersect for the highest observed value for a particular column and row was the cell associating a single fracture with dentulous jaws.

The association between the sites of trauma and the number of fractures was high, the chi-square value being between the 0.01 and 0.001 level of probability (Table 6 ). Detailed inspection of Table 6 reveals that those cells with the greatest observed frequencies for each column are grouped within the top two rows, which designate the "Angle or Body" and "Chin Point" trauma sites. Those cells with the greatest observed frequency for each row of Table 6 are grouped within the two columns which designate 1 and 2 fractures. 
Application of the chi-square test to the "Angle or Body" and "Chin Point" trauma sites demonstrated that the null hypothesis was satisfactorily refuted. The total of the chi-squares for this test was 20.197; with three degrees of freedom, $P=11.345(0.01)$ and $16.268(0.001)$. Thus the association between the angle or body and chin point regions as the sites of trauma, regardless of the number of fractures produced, was very orderly and non-random.

Application of yet another chi-square test to the association between 1 and 2 fractures, regardless of the trauma site, did not yield a chi-square value which was large enough to refute the null hypothesis. Here chi-square $=7.662$, and, with four degrees of freedom, $P=7.779(0.10)$ and $9.488(0.05)$. Thus the null hypothesis for this test - that the number of fractures is not associated for causes other than chance, regardless of the trauma location-was not indicated as being a false assumption.

Two additional chi-square tests of the residual cells in Table 6 did not approach a magnitude which threatened or rendered suspect the null hypotheses involved. There is only one cell in Table 6 in which the highest observed value for a particular column was also the highest observed value for the same row. This is the cell associating one fracture with the angle or body site of trauma.

Two chi-square tests were made to ascertain non-randomness of the association between age by decades and the number of fractures, and the association between age by decades and the location of fractures. Neither of these tests proved significant at or above the 0.01 level of probability. Thus, in each of these two cases, the null hypothesis was sustained, and the associations were due to random causes only.

\section{DISCUSSION}

There was a significant association between the state of dentition and the location of the fracture which was not random. In this light it was noted that, regardless of the fracture site, the association between jaws with individual teeth missing and fully dentulous jaws was not due to chance. With some reservations, this was also found to be true for the relationship between subcondylar and angle or body fracture sites, regardless of the state of dentition.

The association between the site of trauma and the location of fracture was demonstrated to be due to factors other than chance in dentulous jaws. Furthermore, in dentulous jaws the relationship between angle or body and lateral chin impacts was non-random, regardless of the fracture site; this was not true as regards the chin point, chin area, and unknown regions of the jaw. In dentulous jaws when the trauma location was ignored, there was a significant association between angle or body and subcondylar fractures, but not for chin and other areas.

The null hypothesis was refuted when the association between the trauma site and the location of fracture in jaws with individual teeth missing was analyzed. In these jaws, regardless of the locus of the trauma, there was also a non-random association between the angle or body and subcondylar fracture sites, while the chin and other areas were randomly seen areas for fractures. Finally, regardless of the fracture location, the association between angle or body, chin point, and lateral chin trauma sites was not found to be attributable to chance. The reverse was true for the chin area and unknown impact sites.

The result of the chi-square test when applied to the state of dentition and the 
number of fractures indicated that the null hypothesis was not acceptable. With reservations, additional analysis indicated that, regardless of the state of dentition, the association between single and double fractures was due to factors other than chance alone but that the association between dental state and three to six fractures was attributable only to chance.

The site of the trauma and the number of fractures produced proved also to be nonrandom. The association between the angle or body and chin point trauma sites was not a chance occurrence, regardless of the number of fractures. Chance alone was a sufficient explanation for the lateral chin, unknown, and chin area impact site association with the number of fractures.

Certain regularities became apparent when the results of the various chi-square tests were compared. One of these was that, in dentulous jaws and mandibles with individual teeth missing, the angle or body and subcondylar fracture sites association was significant, while chance alone explained the other fracture sites (regardless of the location of the fractures). This same association (or lack of it) was tentatively accepted, regardless of the dental state. There was a significant association between the angle or body and lateral chin sites of trauma, regardless of the fracture site, both in dentulous jaws and in jaws with individual teeth missing, but this was not true for the other trauma sites. In regard to the latter dental state, this was also true of the chin point trauma site, which paralleled the association between the angle or body and chin point trauma site association, regardless of the number of fractures.

One parallel is evident when the individual cells which combined the highest observed frequencies by rows and by columns are compared. This is found in the association between angle or body sites of trauma and angle or body fracture loci in dentulous mandibles and jaws with individual teeth missing.

From the above, it is apparent that the angle or body and the subcondylar regions of the mandible were most susceptible to fractures, for this association was demonstrable regardless of the dental state and regardless of the site of the trauma in dentulous jaws and in jaws with individual teeth missing. Again the angle or body region of the jaw had an association with the lateral chin and the chin point as a significant site of trauma, regardless of where the fracture was produced or the number of fractures; this may be limited to dentulous mandibles or to those in which individual teeth are missing.

Finally, there is some suggestion that angle or body trauma sites had a high association with angle or body fractures on the basis of individual cells with the highest observed frequencies for rows and columns. The authors hasten to point out that this last statement should be investigated in much more detail, since there is no statistical proof of its validity.

Associations between age of the individual, by decade, and the location of the fracture and that between age and the number of fractures per case are not statistically significant.

\section{SUMMARY}

Statistical analysis of 319 case histories of mandibular fractures revealed certain significant associations. For analysis, the data were grouped according to the state of dentition, by the site of impact, by the location of the fractures, and by the number of 
fractures per case. There was a significant association between the dental state and the fracture location. With respect to dentulous jaws, the association and the state of trauma and the location of fractures was proved to be due to other than chance factors. Jaws with a few scattered teeth missing demonstrated that the trauma site and the location of fracture were not due to chance but could be predicted in their occurrence. The state of the dentition and the number of fractures were likewise orderly and not chance events. The trauma site and the number of fractures produced also were non-random. Associations between age of the individual by decade and the location of fractures and that between age and the number of fractures per case proved to be due to chance alone.

\section{REFERENCES}

1. HaGan, E. H., and Huelne, D. F. An Analysis of 319 Case Reports of Mandibular Fractures, J. Oral Surg., Anesth. and Hosp. Dental Service, 19:93, 1961. 